\title{
An Analysis of Regulative Speech Acts in English \\ Contracts - \\ Qualitative and Quantitative Methods
}

\begin{abstract}
This paper deals with the language used to express legal speech acts in simple contracts within the field of English Contract Law. The central objects of study are regulative functions, i.e. directive and commissive speech acts with a particular view to establishing realisation patterns of these rhetorical functions. The hypothesis that the speech acts subjected to analysis are homogeneously distributed linguistic realisations typical for simple contracts is tested by means of partly manual analysis, partly machine-based quantification of the data of investigation. The findings show that statistically significant items are distributed homogeneously in the corpus examined, and that the choice of individual strategies can be interpreted in terms of the face redress required by the socio-pragmatic situation.
\end{abstract}

\section{Background}

The field of legal language is unique with regard to distinctive lexical features, such as technical terms, archaic expressions, etc., and it is renowned for its syntactic complexity, which has given rise to a number of studies concerned with these aspects (see, e.g. Danet 1985:278-87).

Most research studies in the field of pragmatics have been based on nonsequential hypothetical data exemplifying everyday conversation (including work on politeness phenomena, e.g. the work of Brown/ Levinson (1978, 1987) and the growing number of studies based on their theory).

With regard to the written medium, syntactic/semantic studies prevail, and very few studies are concerned with pragmatics and politeness (see, e.g. Myers, 1989, Pilegaard, 1990). Pragmatic studies of legal discourse are 
limited to a few studies (e.g. Kurzon 1986, Werther/ Helmersen 1989, Blom 1991, Trosborg 1991).

In this paper, authentic contracts are analysed for socio-pragmatic occurrence and pragmalinguistic realisation of regulative acts.

\section{Communicative function: regulative speech acts}

Language is critical in regulating human behaviour. For the specific purpose of constructing contracts, language is used as a means of 'ordering human relations', i.e. language is used with a regulative function.

In his taxonomy of illocutionary acts, Searle (1976) outlines two major categories of regulative acts: directives and commissives, with the same 'direction of fit', world-to-words, the illocutionary point of which is the speaker's intention to regulate the world, as opposed to, for example, representative speech acts where the words are adjusted to match the world ('words-to-world').

Establishing classificatory kinship between requests and promises would simplify Searle's taxonomy. However, in his taxonomy the two categories are different:

»whereas the point of a promise is to commit the speaker to do something (and not necessarily to try to get himself to do it), the point of a request is to try to get the hearer to do something (and not necessarily to commit or obligate him to do it).« (1976:12)

Attempts to assimilate the two categories have been made, suggesting either that promises are really a species of requests to oneself (e.g. John Boyd ibid.) or that requests place the hearer under an obligation (e.g. William Alston ibid. and John Kearns ibid.). Searle, however, accepts neither solution but commits himself to »the inelegant solution of two categories with the same direction of fit « (ibid.).

The present framework suggests a classification in which directives and commissives are subclasses of the same category of regulative acts.

In contracts the commitment can be established either as an obligation issued by one party over the other (i.e. directive), or by a party committing him/herself (i.e. commissive). 
Within a very general definition, the nature of a contract may be defined as follows:

»A contract is a legally binding agreement, that is, an agreement imposing rights and obligations on the parties which will be enforced by the courts« (Redmond 1979:19)

Thus the language of simple contracts refers to mutual rights and obligations in relation to promise and consideration, and we shall now consider the "nature" of the underlying linguistic functions for distributing such rights and obligations: directive and commissive acts.

\subsection{Directive acts}

A directive is an illocutionary act by means of which the addresser tries to influence the behaviour of the addressee. Directives are impositive acts which have been defined as follows:

»Impositive speech acts are described as speech acts performed by the speaker to influence the intentional behaviour of the heare

In outlining the terms of the contract, rules are formulated with the intent of ordering human relations. One party of the contract (e.g. principal, seller, franchiser) imposes a certain behaviour on the other party (e.g. agent, buyer, franchisee) and vice versa.

A directive is a face-threatening act involving a threat to the addressee's negative face, which has been defined as »the want of every »competent adult member " that his actions be unimpeded by others « (Brown/Levinson 1987). An addresser issuing a directive attempts to exercise power or direct control over the intentional behaviour of the addressee and in this way intrudes on the right to freedom of action.

The degree with which the addresser tries to impinge on the behaviour of the adressee is referred to as the degree of imposition. In order to lessen the impact of the imposition on the addressee, the addresser has recourse to politeness strategies. The explicitness with which the act to be performed (or not performed in case of prohibitions) is referred to as the directness level of the directive.

\subsection{Directness levels of directive acts}


When issuing a directive, various options are available to the addresser. Within the theory of Brown/Levinson (ibid.), the directive can be expressed 'on record' or 'off record' , i.e. with or without explicit directive force, respectively. If the former option is selected, the addresser can voice the directive with or without face redress by using mitigating devices.

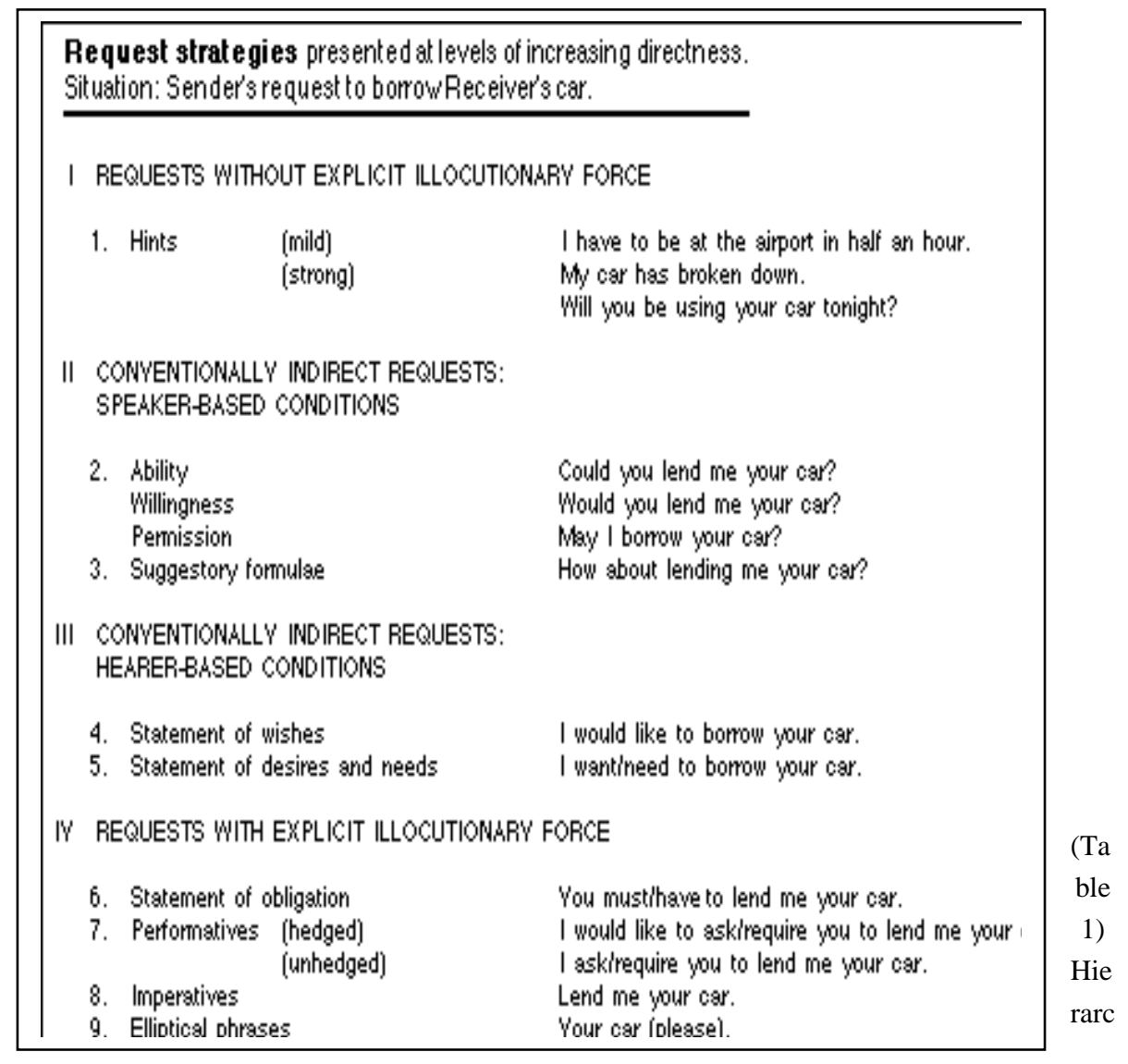




\section{hy of strategies for issuing directives}

Table 1 provides a list of directives used as an instrument for analysing legal speech acts of English Contract Law (Trosborg 1991). In the case of unmodified imperatives and unhedged performative utterances, the directive is phrased explicitly without face redress and serves as an order. Likewise modals like shall and must are employed to impose a high degree of obligation on the addressee. Face redress, on the other hand, can be obtained by means of conventionally indirect directives, either in the form of (i) 'hearer orientated' questions concerning the ability/willingness of the addressee to perform a certain action, e.g. by the use of the modals can/could or will/would or by 'permission statements' through the application of the modals may/might or can/could, or (ii) 'speaker based' want-statements expressing the addresser's desires and needs. Finally, directives can be performed indirectly with no explicit marker of the impositive intent (i.e. 'off record')

These categories are adapted for the purpose of analysing legal contracts (see 3.2.5).

\subsection{Commissive acts}

According to Austin (1962) 'the whole point of a commissive is to commit the speaker to a certain course of action'. Obvious examples are utterances including the verbs promise, vow, pledge, covenant, contract, guarantee, embrace and swear.

Adopting Austin's categories for further development, Searle takes over Austin's category of commissives in its original form with the only objection that certain verbs included by Austin according to Searle "do not belong in this class at all" (1976:11). He refers to verbs such as shall, intend and favour.

Searle repeats that

》Commissives then are those illocutionary acts whose point is to commit the

The sincerity condition is intention. The propositional content always refers to the carrying out of some future action on the part of the speaker. 
The speaker's commitment to carry out the act described in the proposition can be expressed through an explicit performative verb or by means of the modal verb will functioning as an implicit performative:

The Distributor promises/covenants/guarantees...

Each party hereby agrees that it will..

Commissives and directives differ as regulative acts with regard to 'facethreat'. Per definition (as specified by the 'felicity conditions' of promises), promises are in the interest of the hearer (and at the cost of the speaker). The speaker can only promise 'felicitiously' if the intended act is in the interest of the hearer. For this reason, an act of promising is not face-threatening to the hearer. An explicit statement of the promise is therefore desirable, and indirectness and/or hedging would only weaken the obligation and make it legally invalid.

In contrast, directives are issued for the benefit of the speaker and at the cost of the hearer; they are face-threatening acts to be adjusted in communication relative to interlocutor and communicative intention.

\section{Empirical design}

\subsection{The data}

The data of the investigation has been drawn from a corpus of legal language within the specific field of contract law comprising three individual corpora (Danish-English-French). Each corpus consists of $1 \mathrm{~m}$ current words and covers six types of text relevant to the subject: (i) statutes, rules and regulations, (ii) travaux préparatoires, (iii) judgements, (iv) contracts, (v) legal textbooks, (iv) articles in law journals. The data subjected to analysis is the compiled simple contracts.

\subsection{Qualitative methods employed}

The purpose of the analysis was to isolate all occurrences of directive and commissive acts and analyse the pragmalinguistic realisation patterns employed to express the socio-pragmatic function by means of which the parties to a contract are committed. 
A combination of computational analysis and manual tagging was used for examining the contracts for the relevant speech acts.

By applying software, it was possible to quantify lexical items and modal verbs which were identified on beforehand as possible indicators of commissives and directives. However, not all such potential indicators are employed for the sole purpose of realising these functions. Neither was it possible to construct a full set of items which could be trusted to constitute an absolute and inclusive set covering all directives and commissives included in the data.

Prior to the calculation, manual tagging was performed on all potentially ambiguous illocutionary force indicators, so that only indicators of the categories in question were counted. Items unambiguously signalling the identified categories were compiled without prior tagging.

In the following, the classificatory framework outlined in 2.2 (see Table 1 ) is adapted for the purpose of analysing contracts, and crucial aspects are discussed.

\subsubsection{Categories of regulative acts}

The results obtained in the classification of legal speech acts in contract law revealed an almost empty slot for category III (speaker-based preparatory conditions specifying the speaker's needs and desires). As the analysis of contracts showed a similar lack of want- and needs-statements, this category was exempted from the classification.

The unmarked category relates to 'constitutive rules'. Permission is included in the category 'rights', which also comprises 'assignment of benefit' and 'limitation of liability' The scale is enlarged with a fifth category of promises. These categories are discussed below.

\subsubsection{Forms and patterns of realisation of negating elements}

In order to design an adequate domain-specific taxonomy, it has been necessary to establish the pattern of realisation for negations, because the pragma-semantic environment is altered by the presence of such elements, for instance obligation becomes prohibition (e.g. shall -> shall not), 
permission becomes prohibition (e.g. may -> may not), or want/need becomes permission (need -> need not). However, as negating elements do not exclusively appear as verbal phrase modifiers, it has been necessary to map out their patterns and forms of realisation.

The negating elements appear in the corpus predominantly as follows: (i) neither functioning as either a conjunction or a determiner, (ii) nor functioning as a conjunction, (iii) no functioning as a determiner, (iv) the particle not, (v) nothing functioning as an NP-head.

The patterns of realisation seem to follow an overall system: (i) neither occurs either as a conjunction with nor, coordinating two or more NPs (neither the agent nor the manager nor any of their...), or as a determiner for either NP (neither party shall...) or elliptical NP's POM (neither of us shall be liable for...), (ii) nor occurs in the following environments: (a) neither nor, (b) not [VP] - nor [VP], (c) nothing -nor, (d) none of - nor - nor... (iii) no modifies (a) NP-subject (no tenancy is intended to be created thereby), (b) subjective complement NP (this agreement shall be an agreement of no fixed length), (c) subjective complement with elliptical NP (the guarantee shall be of no further effect), (d) object (the officer shall have no entitlement to...), (e) initial PP (in no case will the underwriters be liable to pay...), (f) non-initial $\mathrm{PP}$ (the rights and obligations of the issuers shall in no way diminish...), (iv) not typically modifies VP, (v) nothing always occurs as NP-subject, consequently the following example is prototypical for scores in this respect: nothing in this agreement shall constitute...

\subsubsection{The sub-category »assignment of benefits«}

This category is semantically related to the sub-category permission, however there is a subtle difference in that permissions are always granted by a sender whereas this is not necessarily the case for benefits, although, of course, both permissions and benefits contain a priviledge, which frequently involves an option to make use of such priviledge on the part of the »beneficial party « not acting in agreement with the propositional action uttered in the conditional clause, compare:

»If any such consent is not granted at least five working days before 

Assignment of benefits is a sub-category of the receiver-based conditions and may be realised with or without negation 1 .

The analysis of this kind of legal discourse is problematic, because contrary to e.g. fiction in which supplementary »stage directions « function as a means to differentiate between senders and receivers (»she thought«, »he said«, etc.), it is not always clear from the context exactly who is actually addressing whom in a contract. This may be exemplified by the following statement: »The Agent shall not be responsible for...«

The utterance may be open to two interpretations: (a) in the sender's perspective (the sender being »the Agent $\ll$ ) the utterance becomes an order: »You shall see to it that I am not held responsible for...« in which case the speech act involves an assignment of a right; and (b) in the receiver's perspective (the sender not being »the Agent «) the utterance is more like a commissive speech act: »I shall see to it that you are not held responsible for...«, i.e. a promise or a recognition of the receiver's right.

Therefore the following solution is offered: the utterance listed under assignment of benefits involves a dual function; it distributes a right to whomever entitled to it and a latent duty on the party not entitled to it irrespective of which party makes the utterance.

The modal will gives rise to similar problems. Admittedly our listing of »will « under the obligation sub-group is debatable, as the speech act made may be a commissive or a directive. The underlying speech act implies that one party is committed, while another party gains an advantage. This solution enables us to restrict the category of promises to structures with performative verbs.

\subsubsection{Indicators in modifying clauses}

Indicators may occur in head acts signalling a commissive or a directive act, or they occur in arguments functioning, for example, as a condition (or

1 A pragma-semantically related version of this group is limitation of liability, in which case the right assigned is some kind of debt reduction, restriction as to commitment, etc (e.g. neither party shall be liable for...). 
restriction) on the commissive, a presupposition of the directive, etc. Only indicators signalling the illocutionary functions of directives were scored. The following example serves as an illustration:

$»$ The licence to reside in the premises [...] shall terminate automatically without any notice if the officer shall cease to reside in the premises or upon termination of this Agreement for whatever cause.«(4-006)

Only the structure with the shall in italics functions as a directive; the second shall (in the subordinate clause) is used as a condition on the illocution signalled in the main clause.

\subsubsection{Promises}

The performative verbs typically employed with commissive intention are promise, covenant, undertake, commit, offer, acknowledge, agree, consent. In agreement with Searle (1976:11) verbs like intend and favour (which are suggested by Austin as peformatives) are not treated as performatives, as intentions and favours are "weak" expressions unable to commit the speaker legally. Shall is treated as an implicit performative, though generally with a directive function. The modal will functions as an implicit performative expressing the addresser's obligation to carry out the act described in the proposition. Table 2 below summarises the categories used as an instrument of classification. 
(Table 2) Domain-specific hierarchy of strategies for issuing regulatives

\subsection{Quantification of the data}

\subsubsection{Modals with multiple functions}

In the case of modal verbs which occur with dual/triple functions, manual analysis was required. This applies to the following modals shall, will, may, can and must. In addition to being used with 'mandatory' force (signalling obligation), shall is also used with future reference and in predictions. Similarly, the modal will may be used to express either obligation or prediction. As is well known, the modals may and can express permission or 
possibility, but $\boldsymbol{c a n}$ is also employed to express ability. Must may express obligation (deontic use), or it occurs to express 'logical neccessity'.

Each occurrence of these modals had to be analysed, so that only instances expressing the directive and commissive categories subjected to analysis were counted.

\subsubsection{Realisation of constitutive rules}

Identification of constitutive rules presented problems particularly difficult to solve. These rules are made up of statements with legal effects, but the set of possible verbal items is in principle unlimited with no discrete or easily identifiable items.

An attempt was made to build on previous examples from the analysis of contract law (Trosborg, 1991) extended with the items identified in a smaller number of contracts ( 7 contracts were analysed initially for this purpose). Furthermore, a vocabulary test was run on the computer listing all items ending in $s$. These items were then analysed for their ability to function as the verb of a constitutive rule. The drawbacks of using the items compiled in this way are several. For one thing, verbs of plural nouns, and verbs occurring in the past tense would be left out. For another, it was not possible to limit the number of constructions with the copula $b e+$ adjective as possible fillers of the verb slot.

As it was impossible to construct a full set of items which could be trusted to constitute an absolute and inclusive set of indicators of constitutive rules, manual tagging of this category seemed to be the only possible solution.

However, if the corpus could be shown to be a homogeneous body of text, it was possible to rely on an analysis of part of the text as being representative of the text as a whole. For the purpose of giving information about the homogeneity of the text, a KWIC-concordance analysis ${ }^{2}$ of the body of contracts was performed.

2 Acronym for "key word in context" i.e. a concordance consisting of indexed and alphabetized lexical units. 
By means of forward simulation, the results based on an analysis of a limited part of the text could then be multiplied so that it added up to $100 \%$.

\subsection{The software}

\subsubsection{Comparison of words}

The registration of lexical items within the unmarked category places operational strains on attempts to make a distinct and precise quantification of the corpus material as the realisation potential of such items is theoretically unlimited.

For this reason, we have made a sample analysis on the basis of seven arbitrarily selected contracts 3 . Admittedly, objections may be raised towards this approach for uncertainty, as results may be influenced by particular contractual orientation, textual volume, etc. This has necessitated supplementary tests in order to establish the extent to which the corpus may be said to constitute a homogeneous set, and to this end a new method for measuring two collections of words relatively has been employed. set $^{4}$.

First a few reflections on an adequate tool for such analysis of a sample

The starting point is the need for a method for describing two sets of vocabularies.

A traditional dispersion analysis is an inadequate measure for this purpose, as all existing conventional methods of measurement suffer from a number of shortcomings. A major inadequacy is the fact that although a given dispersion may reveal characteristics of a set of observations, it does not reflect any »frequency deficit « or »frequency surplus «. Since dispersion does not itself describe the characteristics of the individual set of texts examined, dispersion-based methods disqualify for the present purpose.

One crucial criterion is the call for »universal« comparison, as the method of measurement should be independent of textual volume in the sense

3 The file numbers are as follows: 4-001, 4-005, 4-047, 4-048, 4-049, 4-057, 4-067.

4 The overall lines in this section are based on Holmboe's (1991) intervention at the first annual meeting of Datalingvistisk Forening. See also Holmboe (this volume). 
that it should be possible to compare the results of this study with future results of other similar studies, provided that corpora employed in making the comparison have been selected according to the same criteria as employed for compiling the present corpus 5 .

Furthermore, it is imperative that each individual word analysed should be included in both sets (A and B), as for the present study it serves no purpose to make comparisons involving non-existent items. Consequently, the comparison is false in the following instance: (word') in A x (word') in B $\equiv 0$, leaving the comparison true in only the instance in which the element examined is present in both A and B, namely (word') in A x (word') in B >< $\underline{0}$.

As it is useful to operate with minimum and maximum values, a negative value is allocated to $\mathrm{A}>\mathrm{B}$, while a positive value is allocated to $\mathrm{A}<\mathrm{B}$, by applying the minimum value of -1 and the maximum value of +1 forming the span in which the comparison is true (i.e. from the minimum value -1 over the zero point to the maximum value +1 ). Furthermore, it is useful to know which words tend towards either set A or set B - and to which extent - which is why a ratio is allocated to each word, so that words with a preference for A, i.e. rel. fq. (word') in A > rel. fq. (word') in B, is expressed in the following formula:

and words tending $\left(\frac{\mathrm{rel} . \mathrm{fq} . \mathrm{B}}{m-\mathrm{f} \cdot \mathrm{M}}\right)-1=\mathrm{ra}$ towards B, i.e. rel. fq. (word') in A < rel. fq. (word') in B, is expressed in the following formula:

$$
\left(-\left(\frac{r e 1 . f q \cdot A}{-\cdots 1+r \mathrm{C}}\right)+1=r a\right.
$$

5 For an account of the underlying principles for compiling the present corpus, see Dyrberg et al. (1988:209ff). 
In practice, this means that the common set of words will manifest itself within this span with the most frequent words around zero and typical A or B-words tending to pull towards +1 and -1 , respectively. Values outside the common set in which the comparison is false are either specific A- or Bwords. The continuum may be explained graphically as follows:

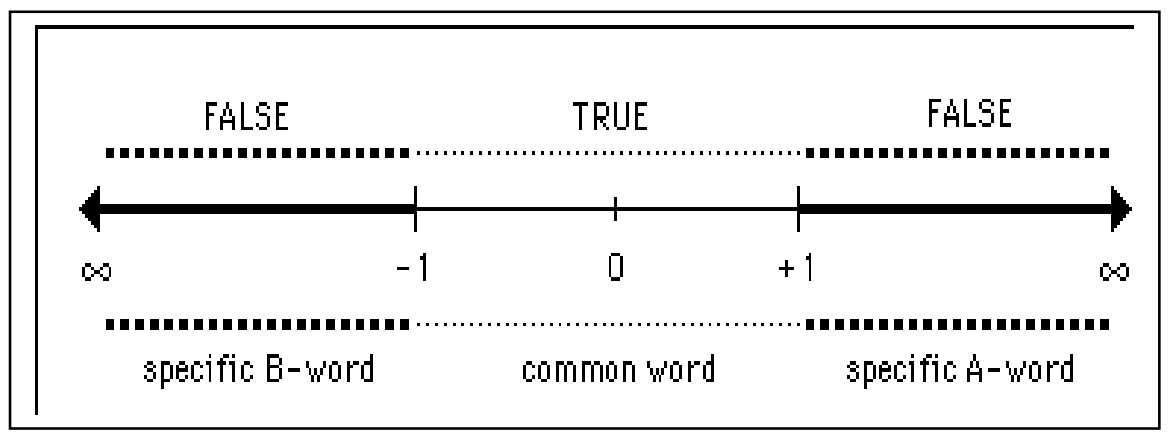

(Fig. 1) Distribution of words in relation to when comparison is true and false

Read from left to right, Figure 3 shows high-ratio words followed by words with decreasing ratios. This approach has the advantage that ratio $-n$ contains the same properties - as regards frequency - as ratio $+n$. This may be described in terms of correlation, as in Figure 4 where words with identical or near-identical ratios will be placed around the diagonal line whether they are highly frequent or not, whereas preference for A or B, i.e. typical A- or Bwords, will pull towards the left bottom corner and the right top corner, respectively. The graphic scale reflects relative frequencies ranging from zero to maximum: 


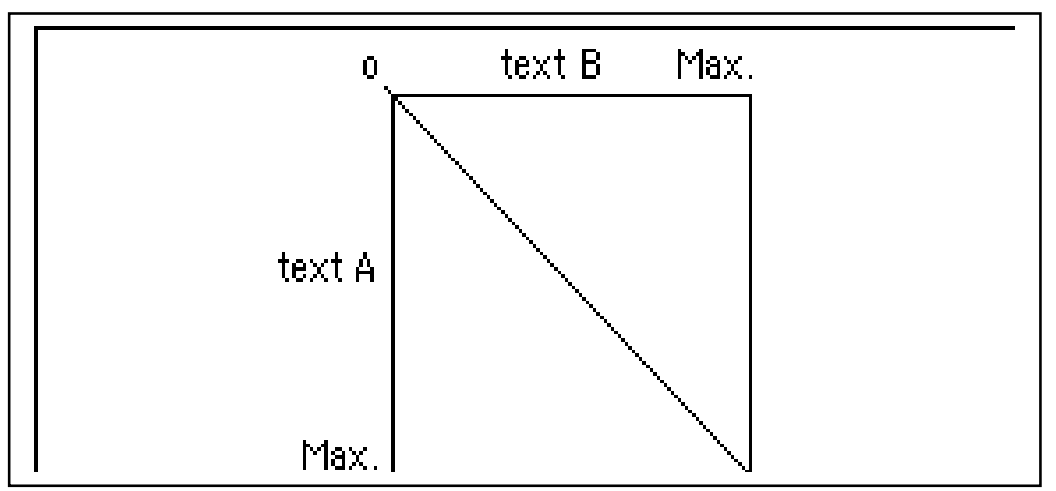

(Fig. 2) Correlation scale for comparison between text A and text B

This correlation scale is our tool for analysing the extent to which subset A may be described as being genuinely homogeneous with principal set $\mathrm{B}$. Words distributed homogeneously on subset A and principal set B are to be found around the zero point, whereas words underrepresented in $\mathrm{A}$ in relation to $B$ seen as a whole, appear between 0 and +1 , pulling towards +1 , and words overrepresented in A in relation to B seen as a whole appear between 0 and -1 , tending towards -1 . Specific B-words are left out of consideration, as they do not occur in subset $\mathrm{A}$, in which case the comparison is false, as mentioned above.

The software employed 6 operates as a three-step program: (i) first, frequency lists (rel. fq.) are established, (ii) second, the lists are run through a merging program calculating ratios, (iii) third, the individual ratios are listed rankwise from -1 to +1 .

\subsubsection{Qualitative criteria for the word comparison method}

The hypothesis that the individual supra-strategies are homogeneously distributed on the whole set form the founding element of the analysis, as we

6 The progam is developed and designed by Henrik Holmboe, Dept. for Computational Linguistics, The Aarhus School of Business - see also Holmboe (this volume). 
postulate that there is no need to analyse the entire corpus in order to establish unmarked strategy realisations in case the generalisation that where a particular observation is true in one case it is true in every instance may be substantiated, so that the sample of seven contracts may be described as homogeneous with the principal corpus set.

The seven arbitrarily selected contracts account for a total of 17,046 current words (10.4\% of total) and $14 \%$ of the total number of contracts which forms an approximal total of 163,500 current words.

The forward simulation is achieved by multiplying each set of occurrences with factor 7.14 to achieve $100 \%$ for the total corpus.

In order to justify the above hypothesis, we have analysed a larger proportion of the corpus manually to investigate the truth value of the trends shown by the quantitative analysis.

Assuming a Poisson distribution, no word is significant unless it occurs at least four times, which is equal to two standard deviations from zero, which again gives a $95.4 \%$ significance, i.e. a word occurring 4 times in the corpus will occur in another corpus selected according to the same underlying priciples with a probability of $95.4 \%$ (cf. Maegaard/Ruus 1981).

This is why we have restricted our analysis to scores honouring such demands, i.e.: (i) modals: may (occurring in category II only), must (occurring in category IV only), shall, will, (distributed on categories I, II, III); (ii) negating elements no, not (significant only in category III).

As modals account for the major part of all speech acts occurring in the supra-strategies, modals - supplemented with significant negating elements will form the basis of our generalisation.

\section{Results}

\subsection{Results of the word comparison}

In order to establish an overall picture of the ditribution of the most central supra-strategy markers in subset A, i.e. $\{1,5,47,48,49,57,67\}$, in relation to principal set $\mathrm{B}$, \{ENGJUR.4\} less $\{2,3,4,9,12,13,25,33,34$, $36,40,41,42,43,55,60,61,65,66\}$ has been analysed. 


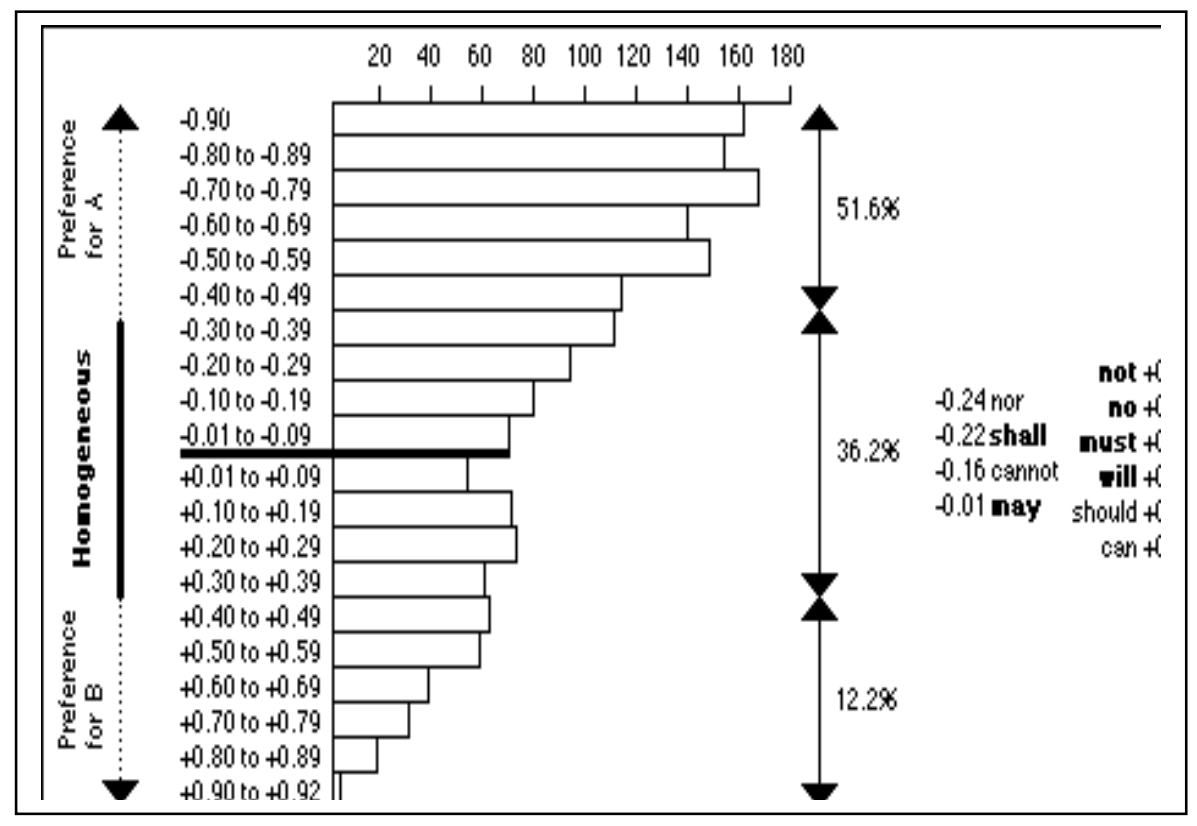

(Table 3) Word comparison bar chart showing distribution of words decimally in relation to zones of homogeneity or preference

A decimally systematised graduation of the ratios (see Table 3 above) has been provided to limit the uncertainty factor involved in making this kind of quantitative analysis, and the zone of homogeneity has been delimited intuitively. It is very important to keep in mind that the various zones should be viewed in terms of scale and graduation as there is no clear-cut borderline between them.

As is apparent from the bar chart in Table 3, the particular words subjected to analysis (see 3.2), namely the modals will $(+0.25)$, must $(+0.23)$, shall $(+0.21)$ and may $(-0.01)$ are actually distributed homogeneously, as their respective deviation from 0 is not all too pronounced. In fact, even lowfrequency items like should (+0.38), cannot $(-0.15)$ and can $(+0.37)$ fall within the zone of homogeneity selected $(-40$ to +40$)$. 
The comparison shows that the most central items of categories I, II, and III - and even some elements tending towards non-significance - are distributed homogeneously in the corpus. One crucial question to be raised in connection with these findings is the question why the prototypical linguistic forms of realisation should be distributed differently. There seems to be a strong indication that the speech acts observed in the corpus of simple contracts are »universals « of this kind of legal discourse; for instance, an analysis of legal speech acts in contracts concerning agencies and sole distributors (Werther/Helmersen 1989) has shown a predominance of modals shall, will and may.

\begin{tabular}{|c|c|c|c|c|}
\hline & & $\begin{array}{l}\text { Entipe corpus } \\
\text { [incl. forward } \\
\text { simulation] } \\
\text { Re1. fq. }\end{array}$ & $\begin{array}{c}\text { Part of cotpus } \\
\text { [maniwally } \\
\text { taged] } \\
\text { Rel. fq- }\end{array}$ & $\begin{array}{l}\text { Differen } \\
\text { in } \mathbb{S}\end{array}$ \\
\hline Direstives & $\begin{array}{l}\text { CAT. I } \\
\text { CAT. II } \\
\text { CAT. III }\end{array}$ & $\begin{array}{l}21.0 \\
16.9 \\
51.3\end{array}$ & $\begin{array}{l}22.3 \\
17.6 \\
50.6\end{array}$ & $\begin{array}{l}-1.3 \\
-0.7 \\
+0.7\end{array}$ \\
\hline Commissives & CAT. IY & 10.9 & 9.5 & +1.4 \\
\hline
\end{tabular}

(Table 4) Distribution of strategies and differences in per cent

As is apparent from Table 4, the difference between the results of the two different approaches, i.e. the analysis including the forward simulation of category I elements not suitable for computerised quantification and the analysis based on manual tagging show very little difference, the total difference being some $2 \%$.

Table 5 on page 109 provides a detailed view of the various patterns of realisation for the individual sub-categories. 


\subsection{The use of regulatives in English contracts}

The corpus of contracts was analysed for the occurrence of regulative acts. Few performatives were used to indicate directive force. Instead, modal auxiliaries were used as 'implicit performatives'. The results (see Table 5 below) show a predominance of direct acts (Cat. III, statements of obligation and prohibition), which amounted to $46.3 \%$ of the total number of observed strategies. Unmarked strategies (Cat. I, constitutive rules) were employed frequently $(22.7 \%)$. In Cat. II, conventionally indirect strategies were only expressed by means of permission statements (5.8\%); besides, 'assignment of benefit' (6.6\%) and 'negated limitation of liability' (3.4\%) occurred. Strategies querying preparatory conditions (hearer's ability/willingness to carry out the desired act) and speaker-based strategies expressing wishes and desires, which occur frequently in everyday conversations (Trosborg, 1991), were noticeably absent.

With regard to the use of performative verbs as regulating devices, performatives were not used at all to express directive force. In contrast, commissive acts were realised by means of performatives explicitly expressing promises $(9.5 \%)$. Obligation expressed by implicit (secondary performatives) realized by the modal will amounted to $4 \%$.

In the following, the realisation types of directive and commissive strategies observed in the corpus are discussed and exemplified.

\subsubsection{Direct directives}

As is apparent from Table 5, direct strategies (i.e. Cat. III) are the most frequently used directives in English contracts. Statements of obligation amounted to $39.5 \%$, and prohibitions to $6.8 \%$. Imperatives and performatives were not observed.

\subsubsection{Obligation}

In order to express obligation in legal contracts, the modal shall is used almost exclusively (38.O\%). Shall is used to express the illocutionary force of an order. The addresser - one party to the contract - directs the other party to do X. By signing the contract, the addressee undertakes the obligation: 
»Commission shall be paid on a quarterly basis and shall be based on the previous quarter's nett sales« (4-001)

»Employees shall work such overtime as the Company from time to time thinks

necessary according to the needs of its business «

As in (4-001), the illocution is frequently constructed by the application of passivisation involving agent suppression, and/or by the use of non-human subject. Those are prominent features of the legal register, and may be explained in terms of face redress in order to reduce the FTA involved in issuing a directive.

\subsubsection{Prohibitions}

In addition to statements expressing obligation, the regulation of behaviour can be made by issuing prohibitions. Again, the modal shall is used almost exclusively ( $6.0 \%$ out of $6.8 \%$ of the strategies observed):

»the Representative shall not be entitled to enter into any contract or obligation

»Nothing in this Clause shall confer any right upon the Distributor to return

on behalf of the Company without the express wr

»The officer shall have no entitlement to any further period of holiday with or

Products purchased by it pursuant hereto or to ref without remuneration unless expressly agreed bet

The three examples reflect some of the different types of negation which were mentioned in 3.1.2.2.

\subsubsection{Rights}

\subsubsection{Permission}

Permission generally issues from some authority, which is often the speaker (addresser) - the performer of the speech act. In contracts, a symmetrical relation holds between the two parties, either of which is able to grant permission to the other party:

»The Hirer may determine the hiring at any time by giving one month's previous notice in writing expiring on one of the days appointed for payment of rent « (4015) 
$\gg$ The Owner hereby grants to the Distributor [...] the sole and exclusive right

»The company hereby gives the officer permission to reside with his wife and to licence, sub-licence and generally to market, $\mathrm{d}$ : children in the dwellinghouse and premises $[\ldots]$;

Statements of permission amounted to $5.8 \%$ of the total number of strategies.

\subsubsection{Assignment of benefit/liability}

The below examples are linguistic manifestations of the sub-categories (i) assignment of benefits, (ii) negated assignment of benefits, (iii) limitation of liability, and (iv) negated limitation of liability, respectively.

»the Company shall have power [...] to carry on its business alone or in association with any one or more persons (whether natural or legal) or by any one or more subsidiary companies « (4-026) »The duty to disclose contained in this clause shall not impose on either party any obligation to develop any such modification »The Carrier shall be relieved of its obligation to perform the Contract to the extent that the performance thereof is prevented $b$ »no liability whatsoever shall be accepted by the Contractor for any alterations or additions carried out in contravention of this Clause « (4-059)

\subsubsection{Constitutive rules}

Statements which do not include performative verbs, or modals functioning as implicit performatives, may still serve the purpose of regulating behaviour. Sentences used to explain or define expressions and terms in the contract or to supply information concerning the application of the statute, or part of it, are part of constitutive rules (cf. Kurzon 1986:23). Examples typically involve lexical main verbs such as mean, apply, include, exclude, which are not performative verbs, constructions with $b e+$ copula: 
»The Agent is responsible for finding out and notifying in detail of Governmental and other requirements in the Territory affecting this Agreement $\ll(4-018)$

Future reference by the use of the modal shall may indicate a constitutive spelling out a rule of the contract with a legal effect.

»ANY notice required to be served upon the Owner or Hirer hereunder shall be deemed to be duly served 48 hours after posting $\mathrm{i}$

\subsubsection{Commissives}

By making a promise a party to the contract commits him/herself before the law. Promises were typically expressed by means of performative verbs, such as agree, undertake, acknowledge, warrant, accept:

»The Supplier warrants to the Customer that the Equipment marketed by the Supplier is believed to be free from defects of wo

»The Licensee acknowledges that the copyright in [...] all written, printed and photographed matter supplied by the Grantor und

The verbs promise and covenant were observed but they were not in frequent use.

\section{Concluding remarks}

\subsection{Explaining the findings}

No detailed comparison of the use of regulatives in legislative texts compared with the use in simple contracts will be provided. A few comments shall suffice.

In both types of legal documents, the category of direct directives dominates with mandatory shall as the single most frequently used subcategory (legislation $21.4 \%$, contracts $38.0 \%$ ).

A difference was observed in the use of explicit performatives in directives compared with commissives. Strategies of the prototype I hereby order you to do $X$ were rarely observed, neither in contract law, nor in contracts, whereas strategies of the type $I$ hereby promise to do $X$ amounted to $9.5 \%$ in contracts.

This difference can be explained with reference to the face-threat involved (see 2.2) in the two acts. When issuing a promise, the speaker commits him/herself to carry out the act specified in the proposition, but does 
not impose on the other party. For this reason a promise is not facethreatening to him/her and the promise can be expressed explicitly by means of a performative verb. When issuing a directive the speaker intends to regulate the behaviour of the other party thereby threatening his/her right to be umimpeded, which might explain why explicit performative verbs are avoided.

When comparing the directives observed in English Contract Law with directives as observed in everyday conversations, the selection of directness levels differs markedly in the two domains. The strategies used most frequently in everyday conversational English belong to the category of conventionally indirect directives (see Trosborg, 1991, for a comparison of directives in contract law with directives in conversational English). Querying the hearer's ability/willingness to perform a given act (Could you spare me a cigarette?/Would you mind mailing this package for me?) amounts to $50.6 \%$ of the total number of strategies observed in conversational English, while statements of the speaker's wishes and desires (I would like you to send me a parts list) amount to $16.9 \%$, altogether comprising $67.5 \%$ of the total number of strategies. These strategies occur neither in contract law, nor in contracts. In legislature and in contracts, the addressee's willingness to perform is not questioned. The authority of the legislature is unquestionable, and in contracts the parties are obligated by their signature. These factors explain why we do not find directives of the kind Can/could/would you do X? in the corpus. This type of directive is by far the most frequent in conversational usage, due to a balance between being adequately polite (conventional indirectness), and a demand for explicitness (the proposition to be performed by the addressee is explicitly stated).

The total absence in the language of the law of want-statements (the speaker's wishes and desires for $\mathrm{X}$ to take place), which in conversation is realized as $I$ want/would like $X$ can be explained with reference to the 'sincerity condition'. This strategy is a statement to the effect that the speaker sincerely wants $\mathrm{X}$ to take place. However, as the legislator's demands become law, when enacted, and the contractor is obligated by his/her signature, there is no point in stating sincerity.

In contrast, the most frequent category in the language of the law and in contracts is direct ordering ( $46.3 \%$ and $47.6 \%$, respectively), which is the category employed least frequently in the conversational data $(9.6 \%)$. As for 
individual strategies, statements employing the modal verb shall are specific to legal English. Imperatives were not observed at all in the language of the law. In everyday conversation, orders are issued downward in rank by means of imperatives (Bring me the file), or the strategy is used as an indicator of solidarity between interactants of equal status (Hand me the paper, will you?).

The modal must (deontic use) was not observed at all as illocutionary force indicator of directives in contract law, and it was employed only infrequently in contracts (0.6\%). Must is used in conversational English in directives issued by authority figures, and it also occurs in statements in which the speaker wants to expresss enthusiasm as to the realisation of the propositional content (You really must go and see that film). The modals should/ought to were utilized only in rare cases in contract law when a directive was intentionally weakened, and not at all in contracts. These modals are used to express suggestions and convey pieces of advice in conversational English.

In legislation, the legislator is in a position of authority over the addressee, which factor is decisive in the selection of directness levels utilized in the language of the law. It explains the high proportion of direct acts and may even influence acts seemingly offering the addresse freedom of action. Similarly, in contracts obligations must be clearly and unambiguously expressed because of the orientation towards the esoteric audience (the courts administering the "rules" of the contract in the case of conflicts).

The occurrence of statements with directive intention without performative marking constituted part of the data in all three domains: $22.9 \%$ in everyday conversations, $39.3 \%$ in the language of the law, $22.7 \%$ in contracts.

The occurrence of statements with directive intention without performative marking observed in both conversational English, English Contract Law and English contracts needs to be commented on. In the conversational data, these utterances are indirect directives (hints), in the sense that the intended directive force can be neglected by a non-cooperative hearer. This is not so with the unmarked statements of the language of the law and of contracts. In spite of the lack of directive markers, these statements belong to the body of constitutive rules which come into function 
as directives by means of the promulgation formula (in contract law) and by means of the signing of the contract (in contractual communication); hence constitutives function as impositive acts on a par with explicit directives.

Statements of permission occur in all three domains. In contract law, permission is supplemented with the categories of assigment of rights and limitation of liability, in contracts with the categories of assignment of rights, assignment of benefits and limitation of liablity.

\subsection{Evaluating the word comparison method}

The software applied in making the word comparison has proved its reliability, since the results provide a reliable reflection of the textual pragma-semantic structures actually occurring in the corpus as substantiated by the underlying qualitative approaches, particularly the manual tagging of a larger section of the corpus. The most astonishing innovation lies in the fact that a method which is in effect non-contextually based may be employed for pragmatic purposes. Supplied with the necessary and sufficient qualitative comments and considerations, this quantitative method seems to be a very powerful tool.

\subsection{Future aspects}

This study may have significant value for didactic and translational purposes, as the discipline »legal language « has so far been non-theoretical to the extent that no tool for explaining the underlying functional phenomena of legal discourse has been constructed.

This study may provide for a more adequate and integrated interlingual output, as regards function, form and contents, as the communicative strategies involved in contractual discourse may be more easily identified by the translator.

The theories of Brown/Levinson do have their shortcomings, e.g. the lack of clear-cut borderlines between categories as touched upon in 2.2.4 (see also Pilegaard 1990, Blom 1991), and these flaws should be observed and noticed. However, studies have detected politeness strategies in even highly specialised discourse, such as scientific language (Myers 1989) and legal language (e.g. Blom 1991, Trosborg 1991), the findings of which support and 
substantiate the substance of the theories of Brown/Levinson which could form the foundation of a trustworthy tool for translational analysis, as traditional translation theory has been prominently weak as regards hermeneutic aspects of interlingual communication. 


\section{References}

Albrecht, L./Møller, A.M.B. (1984): Practical text analysis - how to read between the lines. Copenhagen. Samfundslitteratur

Austin, J. L. (1962): How to do things with words. New York. Oxford University Press.

Blom, B. (1991): Høflighedsstrategisk adfærd i engelske juridiske kontrakter - en deskriptiv empirisk pragmatisk unders $ø$ gelse. Cand.ling.merc. MA thesis, the Aarhus School of Business.

Brown, P./Levinson, S.C. (1978): Universals in language usage: Politeness phenomena. In: E.N. Goody (ed.): Questions and politeness, pp. 56-289. Cambridge University Press.

Brown, P./Levinson, S.C. (1987): Politeness. Some Universals in Language Use. Cambridge University Press.

Curzon, D. (1989): Language of the Law and Legal Language. In: C.Laurén/M. Nordman (eds.): Special Language. From Humans Thinking to Thinking Machines 283-290.

Danet, B. (1985): »Legal Discourse«. In: Handbook of discourse analysis, vol. I, ch. II. London. Academic Press.

Dyrberg et al. (1988): Etablering af juridisk tekstkorpus. In: Hermes 1/ 1988:209ff. The Aarhus School of Business.

Fleck, L. (1935) (1981): The genesis and development of a scientific fact (German ed. 1935), T. Trans (trans.). University of Chicago.

Holmboe, H. (1991): Om sammenligning af ordforråd (intervention at the first annual meeting of Datalingvistisk Forening, June 1991, Aalborg).

Haverkate, H. (1984): Speech acts, speakers and hearers. Pragmatics \& beyond, v. 4. Amsterdam. John Benjamins Publishing Company.

Kurzon, D. (1986): Language of the law and legal language. In: C. Laurén/M. Nordman (eds.): Special Language: From humans thinking to thinking machines. Multilingual

Matters Clevedon/Philidelphia.

Maegaard, B./Ruus, H. (1981): The composition of a text corpus. In: Linguisyica Computionale vol. IV-V. Pisa.

Myers, G. (1989): The pragmatics of politeness in scientific articles. In: Applied Linguistics 10:1-35.

Pilegaard, M. (1990): Pragmatiske aspekter af virksomhedens eksterne kommunikation. Sproglig høflighed i relation til anmodninger (unpubl.). The Aarhus School of Business.

Redmond P. W. D. (1979): General principles of English law. Plymouth. Macdonald and Evans.

Schmitthof, C.M./Sarre D.A.G. (1984): Charlesworth's Mercantile Law. London. Stevens \& Sons.

Searle, J. R. (1969): Speech acts. Cambridge. Cambridge University Press.

Searle, J. R. (1976): The classification of illocutionary acts. In: Language in Society, 5, 1-24. 
Stubbs, M. (1983): Can I have that in writing, please? Some neglected topics in speech act theory. In: Journal of Pragmatics 7:479-494.

Trosborg, A. (1988): Request strategies in natives/non-natives. Paper presented at Second Language Research Forum, Honolulu.

Trosborg, A. (1991): An analysis of legal speech acts in English Contract Law. In: Hermes 1991:6. The Aarhus School of Business.

Werther, C./Helmersen, O. (1989): Konflikt eller konsensus. Del: II. Sproglige analyser af agent- og eneforhandlerkontrakter. ARK 49. The Copenhagen Business School. 